\title{
HLA-B*27 in human health and disease
}

\author{
Silvia Ioana Andrei, Dan Denis Boloca, Olivia Mihaela Popa, Constantin Bara
}

Department of Pathophysiology and Immunology, Faculty of Medicine,

"Carol Davila" University, Bucharest, Romania

\begin{abstract}
$H L A-B^{*} 27$ is one of the most studied $H L A$ allele due to its association with diseases from the spondyloarthritis group, mainly ankylosing spondylitis. This association is still the strongest association described in the literature between an HLA gene and a disease. In the general population, the distribution of HLA-B*27 all over the world seems to vary according to the geographic area of the country. It also has a protective role against certain conditions, especially viral infections.
\end{abstract}

Keywords: HLA-B²7, spondyloarthritis, ankylosing spondylitis, HIV resistance, microbiom

\section{INTRODUCTION}

The human major histocompatibility complex (MHC), due to its immunobiological functions, has a central position in basic and clinical immunology. It includes the human leukocyte antigens (HLA) classes I and II that are involved in presentation of antigenic peptides and have an important role in organ transplantation and in immune-mediated diseases.

HLA-B*27 antigen belongs to HLA class I. It has been studied since 1973 when two scientific groups reported independently a very strong association between HLA-B*27 and ankylosing spondylitis (Brewerton and colleagues and Schlosstein and colleagues) (1). Ankylosing spondylitis (AS) is one of the most common rheumatic diseases and belongs to the spondyloarthritis group. This association is still the strongest association described in the literature between an HLA gene and a disease.

\section{Structure and function}

$H L A-B$ gene is a MHC gene specific for human race. It is part of the MHC class I, together with $H L A-A$ and $H L A-C$ genes. Class I MHC genes represent the genetic support for the synthesis of some proteins on the surface of all nucleated cells in the human body. The proteins encoded by $H L A-B$ gene bind peptides which originate from the interior of the cell and present them to the immune cells. They recognize the fragments as non-self and mechanisms of apoptosis are triggered. There is a large variety of $H L A-B$ genes, which permit each person to react against a large variety of external aggressive agents.

$H L A-B$ gene is located on the short arm of chromosome 6 (6p21.33) starting from the base pair $31,353,866$ until the base pair 31,357,245 (2). As the alleles of the $H L A-B$ gene are very numerous, they have been each given a number, in order to make possible organised studying methods. The most recent allele is $H L A-B * 83$, as mentioned in September 2018 (3).

Due to the genetic association with diseases from the spondyloarthritis group, mainly $\mathrm{AS}, H L A-B * 27$ is one of the most studied allele (4). Its variants, which present very important similarities, have been organised as subtypes: $H L A-B * 2701-H L A-B * 27182$ $(5,6)$, but most of them are not sufficiently represented in population for genetic association studies (7). The ancestral subtype is considered $B * 2705$ and has a high frequency in Caucasian population. Other common subtypes are $B * 2702$ and $B^{*} 2707$ in the Middle East, $B^{*} 2704$ and $B^{*} 2706$ in the East, $B * 2703$ in Africa and $B * 2709$ in Sardinia (8).

HLA-B*27 protein is a heterodimer, as it is composed of two different chains associated by disulfide bonds. The a chain of the HLA-B*27 protein is en- 
coded by the $H L A-B * 27$ gene. The gene has 8 exons and 7 introns (9). The $\beta$ chain of the HLA-B* 27 protein is encoded by the $B 2 M$ gene, located on chromosome 15 (10). MHC molecules are formed in the endoplasmic reticulum and then travel to the cellular surface after proper assembly (11).

The $\alpha$ chain is a heavy transmembrane chain $(43 \mathrm{kDa})$, with an extracellular amino-terminal end and an intracellular carboxy-terminal end. $\beta$ chain is the light chain $(12 \mathrm{kDa})$ and it is located strictly extracellular. Both chains are organised in some domains, each of which has 100-110 amino acids. These domains are the result of intra-chain disulfidic bonds. The a chain is formed of 3 domains. a1 and a2 are located at the amino-terminal end and have almost the same dimensions, even though they are made from extremely different amino acid sequences. As a result, they are known as the polymorphic domains of the HLA molecule. They form a very small cavity, which binds the epitope and presents it to the CD8+ lymphocyte. a3 domain has a constant structure for all the cells which can produce class I HLA molecules, and it is very important in the cooperation with the lymphocyte, as the latter contacts the presenting cell by the CD8 receptor. The $\beta$ chain is composed of a single domain, which has the same amino acid sequence for all the members of the same population. This chain is known as the $\beta 2$-microglobuline (9). It is a self structure and it has a very important role in the graft rejection mechanisms.

The variations between the HLA-B*27 subtypes consist, most frequently, of only one or two different amino acids. These differences usually occur in the heavy chain of the HLA molecule, especially in the peptide-binding groove. The peptide-binding groove is formed by a1 and $\alpha 2$ domains. The linking points between the groove and the peptide are represented by certain sequences named pockets of the heavy chain. The pockets received letters from A to $F(12)$. Genetic variations that determine amino acids changes at the pockets level can impact strongly the function of HLA-B*27 molecule. Important progresses have been made regarding the biochemical and biophysical aspects related to the presence of polymorphisms at the binding sites and their involvement in disease pathogenesis.

Pocket A. It binds the amino-end of the peptide in a complex manner, through five hydrogen bonds. The pocket contains three tyrosines to make the link with the peptide (in positions 7, 59 and 171). The residue Arg62 is a key for TCR recognition (12).
Pocket B. Most frequently, pocket B accommodates an arginine located in the position 2 of the peptide. However, $\sim 3 \%$ of HLA-B*2705 subtype present peptides containing glutamine in the position 2 . Some of these peptides derive from $\beta 2$-microglobuline and in experiments with transgenic rats it was shown to influence the manifestation of AS-like disease (7). On the other hand, pocket B has the amino acid Cys in position 67 which contains a free thiol radical that favours the HLA-B*27 heavy chains homodimerization (13). The new molecule formed in this way has two heavy chains and no $\beta 2$-microglobuline. This kind of molecules stimulates the NK cells receptor KIR3DL2, but it can also stimulate the receptor LILRB2 from the lymphocytes.

Pocket F. This pocket contains the highly polymorphic residue 116 and it is supposed to bind to the carboxy-end of the peptide. However, the pocket sometimes binds to the middle of the peptide. The subtypes associated with AS (HLA-B*2705, HLA-B*2704 and HLA-B*2702) have the aspartic acid in position 116 . On the other hand, the HLA-B*2706 and HLA-B*2709 subtypes, not associated with AS, have tyrosine and hystidine, respectively, in this position. The positions 77 and 114 are also polymorphic (12).

There also exist some preferences for other aminoacids in other positions of the presented peptides. These preferences are different from one subtype to another. B*2705 binds peptides with a carboxy-terminal end which is either aromatic, hydrophobic or positive. On the other hand, HLA-B*2702 can bind only aromatic or hydrophobic carboxy-terminal ends (14).

There have been stated several theories that try to explain the way in which the HLA-B*27 subtypes cause AS. The arthritogenic peptide theory states that HLA-B*27 presents a specific pathogen-derived peptide to the immune system which determines the activation of CD8+ T lymphocytes that will cross-react on molecularly similar self-peptide(s) through an autoimmune process $(11,15)$. A recent study shows that the polymorphisms in the peptide-binding cleft of HLA-B*27 subtypes cause quantitative, not qualitative changes in the HLA-B*27 peptide repertoire which may be relevant for the activation of autoreactive T cells (15).

The homodimerization theory. HLA-B*27 can form homodimers on the surface of the cell. These dimers can be recognised by the immune system and can provoke an immune and inflammatory response. 
However, this capacity isn't specific to HLA-B*27 (11).

The third theory is represented by folding errors that occur in the endoplasmic reticulum (11). The endoplasmic reticulum aminopeptidase 1 and 2 (ERAP 1 and 2) play an important role in the final processes of protein folding within the endoplasmic reticulum. These proteins are going to be attached on the MHC I molecules. Many studies have confirmed a strong association between ERAP1 and Ankylosing Spondylitis. A specific ERAP1/ERAP2 haplotype has been determined to be associated with familial AS (16). When the expression of ERAPI gene becomes lower, the accumulation of HLA-B*27 on the cell surface increases. On the other hand, normal levels of ERAP1 result in a decrease in the accumulation of HLA-B*27 and in the process of dimerization through disulfide chains (17). It has been determined that ERAP1 increases the risk of AS in HLA-B*27 positive people (16). Moreover, it has been discovered that a decrease of ERAP1 modifies only the expression of $H L A-B * 2705$ and $H L A-B * 2704$, which are also subtypes associated with AS. The expression of $H L A-B * 2706$ and $H L A-B * 2709$ remain unchanged after ERAP1 is modified (18).

The heavy chain of HLA class I molecule can also be present on certain cells on its own, even though it is not associated with the light chain ( $\beta 2$-microglobuline). The misfolded proteins from within the cell can be carried on its surface by HLA class I molecules (including HLA-B*27), as well, and not only by HLA class II molecules, as it was believed for a long time. It has been discovered that this function can be performed only by the free heavy chains of the HLA class I molecules. When the HLA class I molecule is completely formed, it can no longer transport the misfolded proteins to the surface of the cell (19).

\section{HLA-B*27 and spondyloarthritis}

The spondyloarthritis represent a group of inflammatory diseases, from which ankylosing spondylitis is the most common affliction (20).

Ankylosing spondylitis has a high prevalence, especially in the populations with high rates of HLA-B*27 positivity. For example, the prevalence of AS in the Caucasian population is between $0.15 \%$ and $1.8 \%(20)$.

In the general population, the distribution of HLA-B*27 all over the world seems to vary accord- ing to the geographic area of the country (21). Following the North to South direction, very high frequencies of HLA-B*27 have been found in Alaskan population and significantly lower frequencies have been reported in the countries from the equatorial area (Table 1). Because HLA-B*2705 is the ancestral subtype, its distribution mirrors very precisely the distribution of HLA-B*27. Consequently, its frequency becomes lower from the North to the South hemisphere. It can be clearly noticed that the ancestral HLA-B*2705 is the predominant subtype in Caucasian populations.

It is considered that the ancestral subtype was the most widespread, but its frequency has been modulated by different environmental factors which are characteristic for each geographical area. It has been suggested that the main factor responsible for the North to South distribution of HLA-B*2705 is malaria and the relationship between the ancestral subtype and the protection against the disease. As a result, the negative selection in the endemic areas has determined lower frequencies of the ancestral subtype compared to other regions. Such an example can be the population from Sardinia, a region well known for its history marked by many years of malaria endemics. The frequency of HLA-B*27 in the AS patients from Sardinia is $70 \%$ (7). Moreover, the HLA-B*2709 subtype was found frequent enough in Sardinian population in order to enable the study of its association with AS. It was present in $20 \%$ of the HLA-B*27 positive people and it was strongly associated with the protection against the disease (22).

Other subtypes significantly associated with AS are HLA-B*2702 and $\mathrm{B}^{*} 2704$. In China there are two predominant subtypes: $\mathrm{B} * 2705$ and $\mathrm{B} * 2704$ (23). $84.74 \%$ of Colombian patients with AS have HLA-B*2705 subtype and $15.26 \%$ have HLA-B*2702 (24). Moreover, the Venezuelan population presented the same pattern of association between HLA-B*2705 and HLA-B*2702 subtypes with AS (7). There has been found no phenotypic difference regarding the clinical manifestations between the patients with HLA-B*2702 and those with HLA-B*2705 (25). On the other hand, HLA-B*2708 subtype has been found in the majority of healthy Venezuelan controls, and it was absent from the population with AS, so this may suggest the association between HLA-B*2708 subtype and the protection against AS (26). However, this subtype has been found in patients with AS in other populations, so it may only be a rare subtype, rather than a protective 
one. This issue occurs in the case of other rare subtypes as well, because they have been found in too few patients or controls in order to sustain a significant association with spondyloarthritis or, on the contrary, a statistically significant non-association (7).

A meta-analysis which evaluated many studies run worldwide stated that HLA-B*2703, HLA-B*2706, HLA-B*2707 and HLA-B*2709 (7) subtypes have a protective role against ankylosing spondylitis. This association with protection against the disease has been suggested especially in the studies developed on Asian peoples (27).

In the Alaskan Eskimo patients diagnosed with spondyloarthritis, the presence of HLA-B*27 was more significantly associated with AS, than with re- active arthritis or with other undifferentiated forms of spondyloarthritis (28).

Among Indian patients with spondyloarthritis tested for HLA-B*27, $43.63 \%$ were positive, the vast majority of which were males, resembling results from other countries (29).

\section{HLA-B ${ }^{\star} 27$ and the intestinal microbiom}

A person hosts 10 bacterial, viral or fungal genomes for each of his cells. This is what Joshua Lederberg stated and started this way the theory that human microbiom has a substantial contribution in the homeostasis of the body. The intestinal microbiota is dynamically linked to the human immune system. As a result, any change which occurs within the structure of the components of the immune systems

TABLE 1. HLA-B*27 frequency in the worldwide general population and in AS patients

\begin{tabular}{|c|c|c|c|c|}
\hline \multicolumn{2}{|l|}{ Country } & $\begin{array}{l}\text { HLA-B*27 positive (\%) } \\
\text { (general population) }\end{array}$ & $\begin{array}{l}\text { HLA-B*27 positive (\%) } \\
\text { (AS patients) }\end{array}$ & Reference \\
\hline \multicolumn{2}{|c|}{ Eskimo (Alaska) } & 40 & & Mathieuet al. (2009) (7) \\
\hline \multicolumn{2}{|c|}{ Norway } & 15.9 & 93 & Popa O. et al. (2010) (30) \\
\hline \multicolumn{2}{|l|}{ Bulgaria } & 10.8 & 88 & Popa O. et al. (2010) (30) \\
\hline \multicolumn{2}{|l|}{ Finland } & 10.4 & 93 & Popa O. et al. (2010) (30) \\
\hline \multicolumn{2}{|l|}{ Romania } & $5.7-10.4$ & 72.1 & Popa O. et al. $(2010)(30,31)$ \\
\hline \multicolumn{2}{|l|}{ Russia } & 10.4 & & Sartakova et al. (2000) (32) \\
\hline \multicolumn{2}{|c|}{ United Kingdom } & 9.5 & $90.2-94$ & $\begin{array}{l}\text { Brown et al. (1996) (33), } \\
\text { Freeston et al. (2007) (34) }\end{array}$ \\
\hline \multicolumn{2}{|l|}{ Spain } & 9.3 & 84.14 & $\begin{array}{l}\text { Ferna'ndez-Sueiro et al. (2004) (35) } \\
\text { Collantes et al. (2007) (36) }\end{array}$ \\
\hline \multirow{2}{*}{$\begin{array}{l}\text { New } \\
\text { Zealand }\end{array}$} & Caucasians & 9.2 & & \multirow[t]{2}{*}{ Roberts et al. (2013) (37) } \\
\hline & Maori & 6.5 & 92.85 & \\
\hline \multicolumn{2}{|l|}{ Indonesia } & 9 & 40 & $\begin{array}{l}\text { Nasution et al. (1993) (38) } \\
\text { Mathieu et al. (2009) (7) }\end{array}$ \\
\hline \multicolumn{2}{|l|}{ Turkey } & 6.8 & 70 & Gunal et al. (2008) (39) \\
\hline \multicolumn{2}{|c|}{ UAE } & 6.4 & 56 & Ziade (2017) (40) \\
\hline \multicolumn{2}{|c|}{ United States of America } & 6.1 & & Reveille et al. (2013) (41) \\
\hline \multicolumn{2}{|l|}{ Greece } & 6 & 80.5 & Alamanos et al. (2004) (42) \\
\hline \multirow[t]{2}{*}{ Italy } & continental & 5 & $68-76$ & Ferri et al. (1982) (43) \\
\hline & Sardinia & 3.5 & 70 & Paladini et al.(2005) $(44,31)$ \\
\hline \multicolumn{2}{|l|}{ Algeria } & 4 & 69 & Ziade et al.(2017) (40) \\
\hline \multicolumn{2}{|l|}{ Iran } & 3.95 & $66.67-73.4$ & Ziade et al. (2017) (40) \\
\hline \multicolumn{2}{|l|}{ China } & $3.6-5.7$ & $90.6-93.6$ & Zeng et al. (2008) (45) \\
\hline \multicolumn{2}{|l|}{ India } & 3.5 & 76 & \begin{tabular}{|l|} 
Mishra et al. (2010) (46) \\
Mathieu et al. (2009) (7) \\
\end{tabular} \\
\hline \multicolumn{2}{|l|}{ Tunisia } & 3.2 & 62 & $\begin{array}{l}\text { Sakly et al.(2009) (47) } \\
\text { Kchir et al. (2010) (48) }\end{array}$ \\
\hline \multicolumn{2}{|l|}{ Israel } & 3 & 79 & Ziade et al.(2017) (40) \\
\hline \multicolumn{2}{|c|}{ Jordan/Qatar } & 2.4 & $72.22-75$ & Ziade et al.(2017) (40) \\
\hline \multicolumn{2}{|c|}{ Iraq } & 2.1 & 84 & Ziade et al.(2017) (40) \\
\hline \multicolumn{2}{|l|}{ Sri Lanka } & 1.5 & 22.8 & $\begin{array}{l}\text { Alba Grifoni et al. (2017) (31) } \\
\text { Kidnapillai et al. (2016) (49) }\end{array}$ \\
\hline \multicolumn{2}{|l|}{ Syria } & 1.4 & 60 & Ziade et al.(2017) (40) \\
\hline
\end{tabular}

AS=ankylosing spondylitis, UAE=United Arab Emirates 
reflects onto the characteristics of the intestinal flora. Such changes have been studied especially in relation to HLA genes polymorphisms (50).

Studies carried out on transgenic rats have proved that the rats in which the human HLA-B*27 gene was introduced, developed a diferent microbiota compared to the control rats. Moreover, the contact with several bacteria resulted in the occurrence of intestinal or joint diseases among the rats, as opposed to the rats which were provided with a germfree atmosphere (51).

Recent studies focused on the link between the spondyloarthritis, the human microbiome and the way it is influenced by several polymorphisms of the HLA-B*27 gene. It has been discovered that the patients with AS have a more permeable intestinal wall than other patients, as well as an altered microbiota. However, a simple sample of stool contains approximately 1000 bacterial species, which makes it extremely difficult to quantify the exact influence of HLA-B27 polymorphisms over each bacteria, or their role regarding the pathogenesis of a disease (50).

A very recent study shows that in AS patients the changes in the intestinal microbiome composition is influenced by HLA-B*27 genotype which support the hypothesis that HLA alleles can increase the risk of the disease through interaction with the intestinal flora (52).

The most important clinical aspects of these studies are the possibility of restoring the intestinal homeostasis using antibiotics, probiotics and prebiotics, as well as a balanced diet or a faecal microbiota transplant (successfully used in very difficult cases of ulcerative colitis and recurrent Clostridium infections) (51).

\section{HLA-B*27 and protection over viral infections}

Although the presence of $H L A-B * 27$ allele represents a predisposing factor for the development of a series of diseases, it also has a protective role especially against viral infections.

Cytotoxic lymphocytes together with some other different mechanisms that have specific roles in the immune response are able to recognise HIV-1 strain, depending on the molecules encoded by the major histocompatibility complex (MHC). The genomic region that corresponds to the $\mathrm{MHC}$ is characterised by a very important polymorphism. Several studies that included HLA-B*27 positive patients deter- mined the association between the presence of $H L A-B * 27$ allele and the protection against HIV-1 strain infection (53).

The $\mathrm{T}$ cytotoxic lymphocytes are activated by the antigen presented by the HLA molecules. These cells play a crucial role in the replication process of HIV. The p24 protein is a viral antigen which is not affected by potential mutations. HLA-B*27 positive patients are able to develop a powerful response against this very stable antigen. The p24 antigen will remain an unchanged target for the immune system, even though the HIV strain will encounter mutations over time. As a result, the immune system keeps the viral replication under control. The $H L A-B * 27$ allele was identified in patients who have not experienced illness signs for more than 10 years. They have a low viral load, their number of CD4+ lymphocytes reduces at a slow pace, and the progression to AIDS is considerably slower as well $(54,55)$.

In case of HIV infection transmitted vertically, from mother to child (before, during or after birth by breast-feeding), the presence of protective HLA alleles in mother influences disease progression in child. The viral load in the mother's blood represents a very important factor for the vertical transmission of the virus. High viral loads can only be possible in HLA-B*27 negative patients. Moreover, it is known that the baby inherits more than $50 \%$ of the mother's $H L A$ genes. As a result, a baby infected by the high viral load present in his HLA-B*27 negative mother, can have no protective allele as well. On the other hand, the child of a HLA-B*27 positive woman will have chances to inherit the protective allele. It was determined that slow disease progression was more pronounced when the children carried non-shared protective $H L A-B$ alleles (55).

Moreover, many studies have shown that the presence of $H L A-B * 27$ allele is associated with a favourable evolution concerning other viral infections as well. The influenza virus, the herpes simplex virus, Epstein-Barr virus and the hepatitis $\mathrm{C}$ virus $(\mathrm{HCV})$ are some of the pathogens which cause a less serious form of illness in HLA-B*27 positive patients (56).

In the acute infections with genotype $1 \mathrm{HCV}$, the presence of HLA-B*27 was associated with high rates of spontaneous reduction in the viral load, and sometimes it even becomes undetectable. However, the studies undertaken until now couldn't establish the association between $H L A-B * 27$ gene and the protection against the infection with the genotype 3 
HCV. The significantly higher frequency of the $H L A-B * 27$ allele in patients who are infected with the subtype a of the genotype $3 \mathrm{HCV}$ over those infected with the type $1 \mathrm{HCV}$ stands as an additional proof for the result of the studies $(54,57)$.

A set of studies analysed the way in which the presence of HLA-B*27 influences the risk of mortality, and they concluded that the presence of this allele increases it only in those patients who have already been diagnosed with one of the diseases associated with HLA-B*27. In many cases, the associated comorbidities had an important impact over the outcome of the studies as well. It is very important to be aware that even though $H L A-B * 27$ allele is present in $85 \%$ of the patients diagnosed with ankylosing spondylitis, only about $5 \%$ of the HLA-B*27 positive general population is ever diagnosed with ankylosing spondylitis $(16,58)$.

\section{REFERENCES}

1. Thorsby E. A short history of HLA. Tissue Antigens. 2009 Aug; 74(2): 101-16.

2. https://www.ncbi.nlm.nih.gov/gene/3106

3. http://hla.alleles.org/alleles/class1.html

4. https://ghr.nlm.nih.gov/gene/HLA-B\#sourcesforpage

5. All the HLA-B*27 recognised by the HLA Nomenclature Comitee in September 2018

6. The allelewhichhavebeenrenamed in thenomenclature of the World HealthOrganisation (WHO) untilthelastedition of the IMGT/HLA databasecanbefound at $h t t p: / / h l a . a l l e l e s . o r g / a l l e l e s / d e l e t e d . h t m l$

7. Mathieu A, Paladini F, Vacca A et al. The interplay between the geographic distribution of HLA-B*27 alleles and their role in infectious and autoimmune diseases: A unifyinghypothesis. Autoimmunity Reviews. 2009; 8: 420-425.

8. Reveille JD, Maganti RM. Subtypes of HLA-B27: history and implications in the pathogenesis of ankylosing spondylitis. AdvExp Med Biol. 2009; 649: 159-76.

9. Weiss $\mathrm{HE}$, Kuon W, Dörner $\mathrm{C}$ et al. Organization, sequenceandexpression of theHLA-B*27 gene: a molecular approachtoanalyze HLA anddiseaseassociations. Immunobiology. 1985; 170(5):367-80.

10. Bâră C. Esențial de Imunologie. București: Editura Bic All, 2002.

11. Sibley $\mathrm{CH}$. Autoinflammation and $\mathrm{HLA}-\mathrm{B}^{*} 27$ : Beyond Antigen Presentation. OcullmmunolInflamm. 2016;24(4):460-9.

12. Uchanska-Zieglera B, Zieglera A, SchmiederbP. Structural and dynamicfeatures of HLA-B ${ }^{*} 27$. Wolters Kluwer Health. 2013; 25(4): 411-418.

13. Vitulano $C$, Tedeschi $V$, Paladini $F$ et al. The interplay between HLA-B27 and ERAP1/ERAP2 aminopeptidases: from anti-viral protection to spondyloarthritis. Clin Exp Immunol. 2017; 190(3): 281-290.

14. McMichael $A$, Bowness P.HLA-B*27: natural function and pathogenic role in spondyloarthritis. ArthritisRes. 2002; 4(Suppl 3): 153-158.

15. Schittenhelm RB, Sian TC, Wilmann PG et al. Revisiting the arthritogenic peptide theory: quantitative not qualitative changes in the peptide repertoire of HLA-B27 allotypes. Arthritis Rheumatol. 2015; 67(3): 702-13.

16. HaroonN,Inman R.D. Endoplasmicreticulumaminopeptidases: biologyandpathogenicpotential. Nature Reviews Rheumatology. 2010; 6:461-467.

17. Tran T, Hong S, EdwanJet al. ERAP1 ReducesAccumulation of AberrantandDisulfide-LinkedForms of HLA-B*27 on the Cell Surface. Mollmmunol. 2016; 74: 10-17.

18. Dashtia N, Mahmoudia M, Aslania S et al. HLA-B`27 subtypes and their implications in the pathogenesis of ankylosingspondylitis. Gene. 2018; 670: 15-21.

19. Dashtia N, Mahmoudia M, Aslania S et al. HLA-B`27 subtypes and their implications in the pathogenesis of ankylosingspondylitis. Gene. 2018; 670: 15-21.

20. Zochling J, Smith EUR. Seronegative spondyloarthritis. Best Pract Res Clin Rheumatol. 2010; 24(6): 747-756.
21. Piazza A, Menozzi P, Cavalli-Sforza LL. The HLA-A,B gene frequencies in theworld: migration or selection? Humlmmunol. 1980; $1: 297-304$

22. Paladini F, Fiorillo MT, Tedeschi V, et al. Ankylosing Spondylitis: A Trade Off of HLA-B ${ }^{2} 27$, ERAP, and Pathogen Interconnections? Focus on Sardinia. Front. Immunol. 2019; 10:35

23. Ghasemi-rad M, Attaya H, Lesha E et al. Ankylosingspondylitis: A state of theartfactualbackbone. World J Radiol. 2015; 7(9): 236-252

24. Martínez B, Caraballo L, Hernández M et al. HLA-B*27subtypes in patientswithankylosingspondylitis (As) in Colombia. Rev Invest Clin. 1999; 51(4):221-6.

25. Johnsen SS, Bakland G, Nossent JC. The distribution of HLA-B*27subtype in patientswithankylosingspondylitis in NorthernNorway. Scand J Rheumatol. 2014; 43(4): 296-300.

26. Cipriani A, Rivera S, Hassanhi M, et al. HLA-B*27 sub types determination in patients with ankylosingspondylitis from Zulia, Venezuela. Humlmmunol. 2003; 64(7): 745-9.

27. Yang T, Duan Z, Wu S et al. Association of HLA-B*27 genetic polymorphisms with ankylosingspondylitis susceptibility world wide: a meta-analysis, Mod Rheumatol. 2014; 24(1): 150-61.

28. Boyer GS, Templin DW, Bowler A et al. Class I HLA antigens in spondyloarthropathy: observations in Alaskan Eskimopatients and controls. J Rheumatol. 1997; 24(3): 500-6.

29. Sonkar GK, Usha. Role of HLA B27 in diagnosis of seronegative spondyloarthropathies. Indian J Pathol Microbiol. 2007; 50(4): 908-13.

30. Popa OM, Bojinca M, Bojinca V et al. Distribution of HLA-B*27 in Romanian spondyloarthritidespatients. International Journal of Immunogenetics. 2010; 10: 1111.

31. http://www.allelefrequencies.net/

32. Sartakova ML, Konenkov VI, Golovanova OV et al. Study of the most oftenencounteredallele of the HLA-B ${ }^{*} 27$ gene in Tuvinian and Russian in habitants of Western Siberia. Genetika. 2000; 36(5): 710-3.

33. Brown MA, Pile KD, Kennedy LG et al. HLA class I associations of ankylosing spondylitis in the white population in the United Kingdom. Ann Rheum Dis. 1996; 55, 268.

34. Freeston J, Barkham N, Hensor E et al. Spondylarthrite ankylosante, positivite de HLA-B27 et utilisation des biothe'rapies, Ankylosing Spondylitis, HLA-B27 positivity and the need for Biologic Therapies. Rev Rhum. 2007; 74, 232.

35. Fernandez-Sueiro JL, Alonso C, Blanco FJ et al. Prevalence of HLA-B27 and subtypes of HLA-B27 associated with ankylosing spondylitis in Galicia, Spain. Clin Exp Rheumatol. 2004; 22, 465.

36. Collantes E, Zarco P, Munoz E et al. Disease pattern of spondyloarthropathies in Spain: description of the first national registry (REGISPONSER) extended report. Rheumatology (Oxford). 2007; 46, 1309.

37. Roberts RL, Wallace MC, Jones GT et al. Prevalence of HLA-B ${ }^{\star} 27$ in the New Zealandpopulation: effect of ageandethnicity. Arthritis ResTher. 2013; 15(5): R158.

38. Nasution AR, Mardjuadi A, Suryadhana NG et al. Higher relative risk of spondyloarthropathiesamong B27 positive Indonesian 
Chinese than native Indonesians. J Rheumatol. 1993; 20(6): 98890.

39. Gunal EK, Sarvan FO, Kamali S et al. Low frequency of HLA-B27 in ankylosing spondylitis patients from Turkey. Joint Bone Spine. 2008; 75, 299.

40. Ziade NR. HLA B27 antigen in MiddleEasternand Arab countries: systematicreview of thestrength of associationwith axial spondyloarthritis and methodological gaps. BMC Musculoskeletal Disorders. 2017; 18:280.

41. Reveille JD, Weisman MH. The epidemiology of back pain, axial spondyloarthritisandHLA-B 27 in the United States. The American journal of the medical sciences, 2013; 345(6): 431-6.

42. Alamanos Y, Papadopoulos NG, Voulgari PV et al. Epidemiology of ankylosing spondylitis in Northwest Greece, 1983-2002. Rheumatology (Oxford). 2004; 43, 615

43. Ferri S, Conighi $C$, Buzzanca $G$ et al. Occurrence of HLA B27 antigen in ankylosing spondylitis in Italy. Rev Rhum Mal Osteoartic. 1982; 49, 355

44. Paladini F, Taccari E, Fiorillo MT et al. Distribution of HLA-B27 subtypes in Sardinia and continental Italy andt heir association with spondylarthropathies. Arthritis and Reumatology. 2005; 52(10): 3319-3321

45. Zeng QY, Chen R, Darmawan J et al. Rheumaticdiseases in China. Arthritis ResTher. 2008;10(1):R17.

46. Mishra MN, SingalV. Humanleukocyte antigen B27 in 453 Asian Indian patients with seronegative spondyloarthropathy. Iran J Immunol. 2010;7(4):252-6.

47. Sakly N, Boumiza R, Zrour-Hassen S et al. HLA-B*27and HLA-B51 determination in Tunisian healthy subjects and patients with suspected ankylosing spondylitis and Behçet'sdisease. Ann N Y Acad Sci. 2009;1173: 564-9.

48. Kchir MM, Hamdi W, Laadhar L et al. HLA-B, DR and DQ antigens polymorphism in Tunisian patients with ankylosing spondylitis (a case-control study). Rheumatol Int. 2010; 30, 939.
49. Kidnapillai S, Sirisena ND,Dissanayake VHW.HLA$B^{\star} 27$ allelefrequency in Sri Lankan patients with spondyloarthritides. Ceylon Medical Journal. 2016; 61(2): 71-73.

50. Rosenbaum JT, Davey MP. Hypothesis: Time for a gut check: HLA B27 predisposes to ankylosing spondylitis by altering the microbiome. Arthritis Rheum. 2011 Nov; 63(11): 3195-3198.

51. Rosenbaum J.T, Asquith M. The microbiome and HLA-B27associated acute anterior uveitis. Nat Rev Rheumatol. 2018. 14: 704-713

52. Asquith M, Sternes PR, Costello ME et al. HLA alleles associated with risk of ankylosing spondylitis and rheumatoid arthritis influence the gut microbiome. Arthritis Rheumatol. 2019 Apr 30;

53. http://omim.org/entry/609423

54. den Uyl D, van der Horst-Bruinsma IE, van Agtmael M. Progression of HIV to AIDS: a protective role for HLA-B*27?AIDS Rev. 2004; 6(2):89-96.

55. CruxNB,ElahiS. HumanLeukocyte Antigen (HLA) andlmmuneRegulation: How Do Classicaland Non-Classical HLA Alleles Modulate Immune Response to Human Immunodeficiency Virus andHepatitis C Virus Infections? Front. Immunol. 2017; 8:832.

56. Neumann-HaefelinC.Protective role of $H L A-B^{\star} 27$ in HIV andhepatitis C virus infection. Dtsch Med Wochenschr.2011; 136(7):320-4.

57. Nitschke $\mathrm{K}$, Barriga $A$, Schmidt J et al. $H L A-B^{\star} 27$ subtype specificity determines targeting and viral evolution of a hepatitis $C$ virusspecific CD8+ T cell epitope.Jhepatol. 2014;60:22-9.

58. Lehtinen K. Mortality and causes of death in 398 patients admitted to hospital with ankylosing spondylitis. Ann Rheum Dis. 1993; 52:174-6. 